4 For the patient, transitions involved in the recovery process include:

a moving away from self-perception primarily as a mental patient

$\mathrm{b}$ getting back to normal

c moving towards discovering a positive self-image

d moving towards feeling able to take control of important aspects of his or her own life

e being cured.

5 It is important that recovery plans for individual patients are:

a standardised

$\mathrm{b}$ individualised c evidence based

d standardised and evidence based

e individualised and evidence based.

MCQ answers

$\begin{array}{lllll}1 & 2 & 3 & 4 & 5\end{array}$

a $\mathrm{F}$ a $\mathrm{T}$ a $\mathrm{T}$ a $\mathrm{T}$ a $\mathrm{F}$

b F b T b t b F $\quad$ b T

c $\mathrm{F} \quad \mathrm{c} T \quad \mathrm{~T} T \quad$ c $\mathrm{T} \quad \mathrm{c} T$

d $\mathrm{T} \quad \mathrm{d} F \quad \mathrm{~d} \mathrm{~F} \quad \mathrm{~d}$ T $\quad$ d T

e $F$ e $F$ e $T$ e $F$ e $T$

\title{
INVITED COMMENTARY ON The rediscovery of recovery
}

Who could possibly be against 'recovery'? After all 'recovery' is, according to the Shorter Oxford English Dictionary,

\footnotetext{
'the restoration or return to a former, usual, or correct state or condition, as health, prosperity, stability, etc. ... the cure of an illness, wound, etc.' (Brown, 1993).
}

It is obvious from the foregoing that 'recovery' is a positively valued and desirable course of events. So far, so good. It is this commonplace word, a firmly enshrined and easily understood word, that is the central thesis of Roberts \& Wolfson's article (2004, this issue). Yet, the assumptions and thrust of their paper leave a degree of disquiet that is both palpable and difficult to define. It accurately identifies the origins of the need to consider a reconceptualisation of the term recovery as understood in medicine. These include the increasing and to be welcomed parity in the doctor-patient relationship and the desire of many patients both to abjure the negative connotations of diagnosis and to become more selfreliant in defining personal goals and aspirations despite illness. There is no doubt that negative expectations of health care professionals can influence outcome. The personal accounts of such writers as Janet Frame (1990) support this. Furthermore, it is true that objective and reproducible assessments of outcome that ignore the subjective and personal experience of the patient tell only part of the story - and the part that patients are least interested in. The agglomerating principle inherent in description of populations can appear cold and inhuman and can also be alienating to lay observers. Finally, Roberts \& Wolfson describe the principles underlying recovery and the operation of a recovery-based service. Many of their comments are welcome.

So why my disquiet? Essentially, they argue for a redefinition of the term 'recovery' such that it would cease to mean restoration to health but rather the capacity to 'live well with enduring symptoms and vulnerabilities [which would open] the possibility of recovery to all' (my italics). They pursue their case by citing the fact that governments on both sides of the Atlantic and in New Zealand have endorsed this paradigm shift, as if to say that this legitimisation by governments both authenticates and authorises a change in use of language or, as some might say, a misuse of language. What is certain is that the involvement of governments in this endorsement of a peculiar departure in ordinary language use demonstrates that we are here dealing with the politics of health care and not the clinical aspects.

There are other objections to the case that Roberts \& Wolfson make. For example, they state that " "wellness" and "illness" may be considered as independent variables'. So, I suppose, it would be perfectly reasonable to assert 'I feel very well, but 
my gout is killing me' or 'I feel miserable, I can't sleep, my life isn't worth living, but I'm very well'. There is a limit, I think, to how far language and the concepts that it embodies can be stretched to accommodate our desires not to accept what is negative and emotionally intolerable. But life has much that is painful, discomforting, demeaning and plain bad. Renaming these events or denying their obdurate reality is perhaps unhelpful to those who suffer. In any case, as doctors we have a fiduciary duty to be truthful that transcends the wish to please all.

The all-too-predictable claim is that it is the failings of the medical model that make possible the reality that patients do not all recover, or perhaps even that lack of recovery is demonstrably the failure of the medical model. Whatever the case, it seems clear that the duty of the doctor is to establish as reliably and accurately as possible the course and outcome of clinical conditions. It is also the duty of doctors to continue to work to improve the treatments available in order to maximise the likelihood of recovery, and here I mean real recovery, i.e. restoration to health. We would not normally speak of recovery in Alzheimer's disease, motor neuron disease, multiple sclerosis or Parkinson's disease unless there was empirical evidence of such recovery. It seems obvious to me that a redefinition of the term 'recovery' in order to give hope is to build hope on illusion. Hope, even in the midst of the direst circumstances, is possible and necessary but it is neither dependent on nor anchored to illusion.

To return to my starting point. Who could possibly be against 'recovery'? From Roberts \& Wolfson's point of view, the answer is the threatened and conservative clinician. In truth, the disquiet that accompanies a redefinition of language as radical as this is not simply to do with conservatism or underlying paranoid anxiety. It is recognition that the appropriation of ordinary words to describe the world in ways totally opposed to the original meaning carries with it the risk of alienating people further from the group proposing to use the words in this way. That is not to say that this phenomenon is unique to the mental health setting. Words drift in meaning and can come to mean the opposite of what they originally denoted.

What is undoubted in Roberts \& Wolfson's paper is their humanity and compassion. And these I believe to be shared by many others, including the community of clinicians working in the mental health arena and, of course, the proponents of the 'recovery movement'. In other words, compassion is not exclusive to those who propose a redefinition of the term 'recovery'.

\section{References}

Brown, L. (ed.) (1993) The New Shorter Oxford English Dictionary. Oxford: Clarendon Press.

Frame, J. (1990) An Autobiography. London: Women's Press. Roberts, G. \& Wolfson, P. (2004) The rediscovery of recovery: open to all. Advances in Psychiatric Treatment, 10, 37-49.

Femi Oyebode Professor and Head of the Department of Psychiatry, University of Birmingham, Queen Elizabeth Psychiatric Hospital, Mindelsohn Way, Edgbaston, Birmingham B15 2QZ, UK.

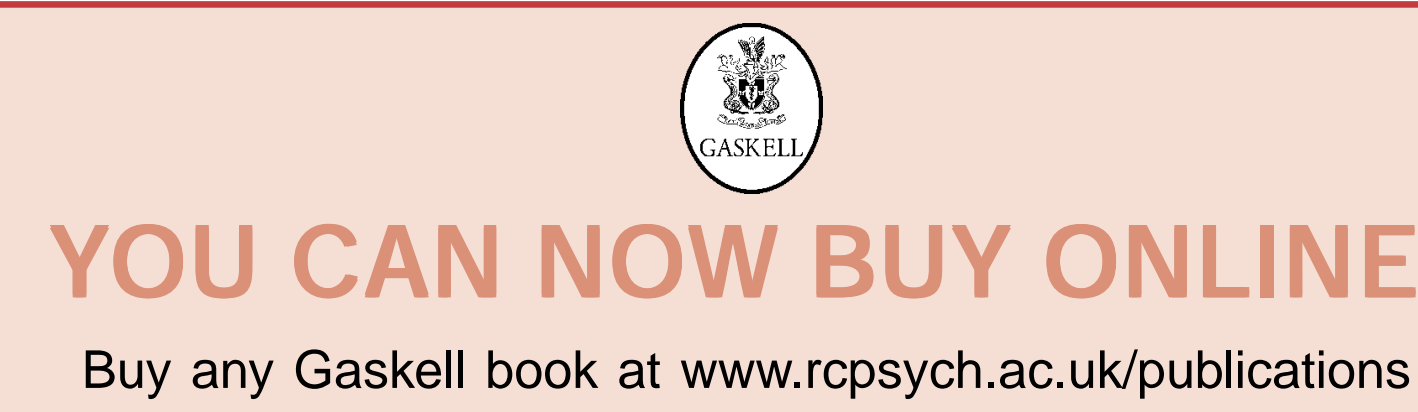

